\title{
Uma intervenção em uma instituição de longa permanência para idosos: a animação recíproca da discussão ${ }^{12}$
}

Mylène Zittoun ${ }^{3}$

Yves $\mathrm{Clot}^{4}$

\section{Resumo}

Este artigo trata de um dispositivo de intervenção que visa instituir na organização do trabalho o conflito dialógico sobre a qualidade do trabalho, considerado como um meio de desenvolver especificamente os recursos organizacionais para desenvolver a saúde no trabalho. Através da criação de uma nova função, o profissional de referência ${ }^{5}$, e da instituição de um dispositivo organizacional - a instância de diálogo sobre o métier (IDM) -, mostra como a divisão hierárquica do trabalho pode ser enriquecida para transformar a organização. Propõe também uma via possível de desenvolvimento na prática da intervenção na clínica da atividade. Baseia-se em uma intervenção realizada desde 2014 em um estabelecimento público médico-social com auxiliares de enfermagem e auxiliares médico-psicológicos da Instituição de Longa Permanência para Idosos e do lar de acolhimento medicalizado para adultos deficientes que fazem parte dessa estrutura. $\mathrm{O}$ artigo apresenta como o trabalho inicial de coanálise da atividade dos profissionais em autoconfrontação cruzada permitiu instituir, por um lado, a função do coletivo de trabalho como meio de ação na organização e, por outro lado, as instâncias de deliberação e decisão sobre o métier. Palavras-chave: Intervenção; Saúde; Instituição de Longa Permanência para Idosos; Qualidade do Trabalho; Transformação Organizacional; Conflito Dialógico.

\section{Une intervention dans un établissement d'hébergement pour adultes dépendants: L'animation réciproque de la} discussion

\section{Résumé}

Cet article traite d'un dispositif d'intervention visant à instituer dans l'organisation du travail le conflit dialogique sur la qualité du travail envisagé comme un moyen de développer spécifiquement les ressources organisationnelles pour développer la santé' au travail. II montre, à travers la création d'une nouvelle fonction, le " référent-métier », et l'institution d'un dispositif organisationnel, l'instance de dialogue sur le métier (IDM), comment peut être enrichie la division hiérarchique du travail pour transformer l'organisation. II propose également une voie possible de développement dans la pratique de l'intervention en clinique de l'activité. Il s'appuie sur une intervention conduite depuis 2014 dans un établissement public médico-social avec des aides-soignantes et des aides médicopsychologiques de l'EHPAD et du foyer d'accueil médicalisé pour adultes handicapés de cette structure. L'article présente comment le travail initial de co-analyse de l'activité des professionnelles en auto-confrontation croisée a permis d'instituer, d'une part, la fonction du collectif de travail comme moyen d'action dans l'organisation et, d'autre part, des instances de délibération et de décision sur le métier.

Mots-Clés: Intervention; Santé; établissement d’hébergement pour adultes dépendants ; Qualité du Travail; Transformation organisationnelle; conflit dialogique.

\footnotetext{
${ }^{1}$ A primeira versão deste texto foi publicada em: ZITTOUN, M.; CLOT, Y. Une intervention dans un EPHAD: I'animation reciproque de la discussion. Psychologie du Travail et des Organisations, v.26, n.1, p.56-70, mar. 2020.

${ }^{2}$ Tradução por Profa. Dra. Flávia Fazion. Professora colaboradora da Universidade Federal do Paraná (UFPR).

${ }^{3}$ CRTD, CNAM, Paris-FR, m.zittoun@free.fr

${ }^{4}$ Professeur émérite de psychologie du travail au CNAM, Paris-FR, yves.clot@lecnam.net

${ }^{5}$ Em francês o termo usado é "référent-métier". Um profissional reconhecido e escolhido por seus pares para agir como intermediário junto à hierarquia. (CLOT,Y. Prendre ses responsabilités? De la santé au droit. Sociologie du Travail, v.61, n.2, abr.-jun. 2019, [Online]). Disponível em URL: http://journals.openedition.org/sdt/17996; DOI: https://doi.org/10.4000/sdt.17996. Acesso em: 05 jun. 2019.
}

Periódico Horizontes - USF - Itatiba, SP - Brasil - e021034 


\section{Introdução}

Nas organizações contemporâneas, os psicólogos do trabalho são constantemente confrontados com uma pergunta incômoda: é possível melhorar conjuntamente performance e saúde? (BONNEFOND, 2017). Diante dessa questão, a prática de intervenção na clínica da atividade encontra limites em sua ação (KOSTULSKI et al., 2011). Foi o que estimulou a concepção de dispositivos de intervenção para instituir, na organização do trabalho, o conflito dialógico sobre a qualidade do trabalho, a fim de desenvolver especificamente os recursos organizacionais (CLOT; SIMONET, 2015; QUILLEROU; CLOT, 2013).

Um desses dispositivos, o recurso aos profissionais de referência, foi implantado em diferentes campos: na indústria automobilística (BONNEFOND, 2016), no departamento de limpeza de uma coletividade territorial (BONNEMAIN, 2019), no setor médico-social (ZITTOUN; LARCHEVEQUE, 2018).

Neste artigo mostraremos como, em uma intervenção em curso neste último, foi explorada uma via de ação para esse propósito - uma via possível de transformação, selecionada entre várias outras (MIOSSEC; CLOT; BOUCHER, 2014), para a prática de intervenção em clínica da atividade. Aqui discutiremos também o que a distingue de outras práticas de intervenção que visam à transformação organizacional.

\section{Contexto e demanda social}

A intervenção que é objeto deste artigo acontece desde 2014 em um estabelecimento público departamental (EPD) fora da capital francesa (Paris). Local de vida e cuidados, com capacidade de acolhimento de 501 lugares, destinado a acompanhar idosos dependentes e adultos deficientes respectivamente distribuídos em dois polos: um de geriatria, o outro para adultos deficientes.

Três convenções foram aprovadas pela Equipe de Psicologia do trabalho e pela Clínica da atividade do CRTD do Conservatoire National des Arts et Métiers de Paris - CNAM. Cada uma 
delas dizia respeito a estes dois polos. Interessamo-nos aqui pelas duas primeiras: uma visava à coanálise da atividade do pessoal de enfermagem para agir sobre sua saúde no trabalho, tendo em conta as dimensões psicológicas e sociais em jogo. A outra ampliava a primeira e tinha por objeto o funcionamento da organização do trabalho em um perímetro definido.

A demanda inicial foi feita pelo diretor do estabelecimento, que desejava experimentar um dispositivo de intervenção em clínica da atividade, pois se viu confrontado com a degradação do clima social em uma unidade de cada um dos polos: do lado da geriatria, o estabelecimento de hospedagem para adultos dependentes (EHPAD), onde vários agentes se queixam do estilo de gestão do seu gestor; e, em menor medida, do lado dos adultos deficientes, um lar de acolhimento medicalizado (FAM).

Alertada por uma das duas organizações sindicais do estabelecimento sobre os conflitos na EHPAD, a Agência Regional de Saúde (ARS), organismo de financiamento e tutela deste estabelecimento público, propõe mobilizar um Contrato local de melhoria das condições de trabalho (CLACT), o que permitirá a mobilização de fundos específicos para a melhoria das condições de trabalho ou para a prevenção de riscos psicossociais. A ARS irá manter este segundo eixo, "deixando na sombra a função do trabalho para a saúde" (MIOSSEC; CLOT, 2011; ROUAT; SARNIN, 2019). De fato, há uma ideia generalizada de que os métiers da "dependência" apresentam riscos em si mesmos que merecem cuidados específicos (CHAMBON; PICHON, 2018). Esta "tentação compassiva" pode levar a "novas prescrições comportamentais", ainda que as intervenções possam ter um destino diferente daquele de uma normalização das condutas e do trabalho (ROUAT; SARNIN, 2013).

De fato, é melhor para a sua saúde que o profissional "deixe de se sentir objeto em um meio de restrições, para se perceber sujeito em um meio de organização" (CANGUILHEM, 2015, p.129). O diretor do estabelecimento defendeu na ARS o interesse em mudar o paradigma de prevenção e experimentar uma abordagem não mais exclusivamente centrada na identificação de riscos ou fragilidades individuais, mas sim no trabalho, nos seus critérios de qualidade, no desenvolvimento do métier em relação com os recursos psicossociais da organização do trabalho (MIOSSEC et al., 2010). Ele também levará sua demanda para análise por suas equipes e pelas organizações sindicais. Todos o seguirão com um nível de engajamento que irá evoluir durante a 
intervenção.

Finalmente, uma primeira convenção de 18 meses, intitulada "Dispositivo de desenvolvimento de recursos psicossociais favoráveis à saúde e eficiência no trabalho", foi assinada em acordo com as organizações sindicais.

O perímetro envolvido será, portanto, o EHPAD, com uma capacidade de 98 lugares para 45 agentes, e o FAM em questão, com uma capacidade de 45 lugares para 45 agentes. A diferença de recursos humanos empregados nestas duas unidades não é específica deste estabelecimento - é o reflexo da diferença na forma como os campos da deficiência e da velhice são tratados em nível nacional. A questão dos recursos humanos será, portanto, um aspecto importante no EHPAD. Os auxiliares de enfermagem (AS) e os auxiliares médico-psicológicos (AMP) farão parte destes dois perímetros - o EHPAD e o FAM. Pessoal majoritariamente feminino, pouco qualificado e pertencente ao mesmo corpo. Deste modo, por terem esses agentes o mesmo objeto de trabalho, nos é explicado que exercem o mesmo métier e, portanto, podem fazer parte dos mesmos coletivos mobilizados. Este foi o caso, mas diferenças intrínsecas na concepção de cuidados - mais centradas na higiene e no conforto para os AS, e na animação e na educação para os AMP - aparecerão, no entanto, durante a segunda ação. E desempenharão um papel importante no trabalho que será realizado.

\section{Primeiro dispositivo de intervenção: desenvolver as funções psicológica e social do coletivo, para promover a saúde no trabalho}

O dispositivo de intervenção começa por um trabalho minucioso da demanda com os diferentes atores: chefe do estabelecimento, equipe de direção, gestão, organizações sindicais, médico do trabalho. Esta etapa fundamental, antes de considerar a fase de trabalho de campo, assegura-se do engajamento de cada um deles, a fim de prevenir o risco de "prejudicar o processo de intervenção" (ROUAT; SARNIN, 2019, p.353).

Esta primeira ação, implementada com Laure Kloetzer e Y. Clot, visava ao desenvolvimento do coletivo como meio de prevenção da saúde no trabalho (FERNANDEZ et al., 2003; FERNANDEZ, 2008). Nesta perspectiva, foi mobilizado o método das autoconfrontações 
cruzadas (ACC), descrito em outras publicações (CLOT, 2008; CLOT et al., 2001; DUBOSCQ; CLOT, 2010). Consiste em colocar os profissionais em condições de realizar, com o interveniente, a coanálise da sua própria atividade de trabalho, para transformá-la, se necessário; e procura desenvolver as funções do coletivo, a fim de imaginar novas possibilidades de pensar e agir individualmente. A implantação deste método é agora um pré-requisito e um meio a serviço da transformação organizacional prevista (QUILLEROU; CLOT, 2013).

O dispositivo mobilizou e se articulou em dois níveis de ação:

- o campo, com a criação de um coletivo de trabalho em cada unidade;

- em nível do estabelecimento, com a organização de um comitê de acompanhamento por polo, composto pela equipe de direção, pela gestão, por representantes sindicais, pelo médico do trabalho, pelos intervenientes do CNAM e, no momento certo, pelos coletivos engajados.

\section{Nos coletivos de trabalho, ter a experiência do "diálogo simples" sobre o trabalho: a função psicológica do coletivo}

Depois de ter sido apresentado o dispositivo metodológico em cada uma das duas unidades envolvidas no perímetro da intervenção, 16 agentes ofereceram-se para participar nos grupos de trabalho: oito mulheres disponibilizaram-se para a EHPAD, oito mulheres e um homem para a FAM. Três pares na EHPAD e quatro na FAM desejaram experimentar o método ACC. Sem colocar à frente as questões de disputa interpessoal ou dos recursos humanos, sugerimos aos agentes fazer um desvio e escolher sequências de atividades que fossem importantes para eles e nas quais seriam observados e depois filmados. Após terem discutido entre eles na presença dos intervenientes, os da EHPAD selecionaram a preparação e a distribuição do desjejum, a higiene, o jantar, o deslocamento dos residentes para um espaço de atividades. Os da FAM escolheram a higiene, as três refeições, a preparação para partir para uma atividade externa. Os agentes comentaram então, sozinhos, os seus filmes de atividade na presença do interveniente - esta é a autoconfrontação simples (ACS); depois, com o outro agente filmado na mesma sequência de atividade - esta é a autoconfrontação cruzada (ACC). Todos esses encontros foram 
filmados.

Em razão do dispositivo que põe em prática, a ACC é um espaço tempo diferente (CLOT, 2008) que organiza "artificialmente" as condições do desenvolvimento da atividade. Cada etapa é uma oportunidade de espantos e surpresas. Durante a ACS, ocorrem os espantos e as surpresas do agente, ligados ao caráter inédito da situação, à redescoberta dos seus modos de fazer e dizer, à natureza das perguntas do interveniente, centradas nos detalhes da atividade. É também a ocasião para o interveniente manifestar-se sobre os seus espantos e surpresas durante as observações que realizou, as captações das imagens, o que vê na tela e as reações que observa no profissional enquanto ele se observa fazer. Durante a ACC, somam-se a descoberta das diferenças nas formas de fazer do colega na mesma situação, a aprendizagem de colocar em discussão a comparação e a confrontação de suas diferenças, espontâneas e/ou nutridas pelo interveniente. Aprendizagem de uma natureza particular, "este trabalho de comparação põe em marcha um processo que visa interferir nos funcionamentos habituais, sendo assim, o princípio da comparação tem a ver com o afeto e as emoções" (BONNEMAIN, 2019, p.3). É a função afetiva da comparação. Porque se trata, de fato, de organizar uma "circulação das maneiras de fazer e dizer entre os profissionais de um meio", a função afetiva é igualmente indispensável para o desenvolvimento da atividade, acrescenta Bonnemain. Apoiando-se em Bonnefond (2017), em Clot (2017) e em Vygotski (2003), o autor pondera que a comparação coloca 'em atividade' a afetividade dos sujeitos até o desenvolvimento eventual da atividade prática dos agentes. Se a "disputa" entre os operadores é motor para o desenvolvimento do diálogo e do pensamento, é porque é desconcertante (BONNEMAIN, 2015; POUSSIN, 2014). O que se julgava justificado e estava incorporado a ponto de organizar a atividade até agora, pode se mostrar desorganizado pela discussão em curso, surpreendido no inesperado das trocas. A comparação constitui uma condição importante no desenvolvimento de disputas profissionais, que por sua vez podem produzir energia suficiente para a migração dos recursos exteriores para a própria atividade do sujeito. A troca, portanto, sempre envolve uma avaliação tingida de afetividade (BAKHTINE, 2003). O afeto é esse devir da atividade que equilibra os esperados e os inesperados, essa oscilação entre formas de passividade que tentam reduzir o inesperado ao que já conhecemos, e formas de atividade que fazem do inesperado o meio de fazer uma experiência nova e inédita 
(BONNEMAIN, 2015). No cerne do poder de agir, ele, o afeto, é, ao mesmo tempo, um objeto e um instrumento para o interveniente engajado nesse tipo de intervenção clínica.

A surpresa ou o espanto, que são meios de desencadear a conflitualidade e a afetividade no princípio da comparação orquestrada pela condução do interveniente, entretanto o atravessam também. Neste trabalho sensível de desenvolver a comparação entre as maneiras de fazer, de desconstruir os discursos acordados sobre os impedimentos habituais, o interveniente mobiliza uma atividade transferencial entre os diferentes registros do métier, pessoal, interpessoal, transpessoal e impessoal (PERROT, 2017; PERROT, 2019; SCHELLER, 2013). Por metáfora, espécie de "estabilizador" que compensa os cortes na vitalidade do diálogo, o interveniente conduz e dosa essa atividade, para que essas diferenças permaneçam discutíveis, suportáveis (REILLE-BAUDRIN; ZITTOUN, 2015). A benevolência e o concreto permanecem nesse questionamento regulado pelo método: "O bom com vocês é que o diálogo é simples, ao contrário do que vivenciamos em outros encontros", disse uma auxiliar médico-psicológica. Essa simplicidade resulta de uma atenção clínica aplicada às deliberações sobre os detalhes que importam; por exemplo, a preparação do chocolate quente para o café da manhã, o tamanho da colher usada para alimentar os residentes, a função da higiene, a composição das refeições. Nesses momentos, os agentes vivenciam a função psicológica do coletivo como recurso em sua atividade individual.

Esse trabalho continua durante os comitês de pilotagem, instância onde esse detalhe assume seus direitos na organização, passa a ser objeto de diálogos com a direção e as organizações sindicais. Centraremos nossa atenção em uma sessão na qual os agentes associados ocupam um novo lugar no dispositivo de intervenção, garantindo uma função social diferente. Os resultados obtidos durante as ACC são aí materializados na forma de montagens de vídeo, compostas por trechos de filmes da atividade e da ACC, escolhidos pelos intervenientes e validados pelos profissionais. Duas montagens, uma de cada polo - uma durante a intervenção e a outra no final -, foram apresentadas a cada comitê de acompanhamento. Este artefato tornou visível a natureza do diálogo prático entre os agentes e o trabalho coletivo realizado. A descoberta da heterogeneidade nas maneiras de realizar uma mesma tarefa; a exigência aplicada à análise dos detalhes, como a preparação do chocolate, por exemplo; a "coragem" dos agentes 
em expor os limites e as disfunções de seu métier; a engenhosidade das soluções que eles propõem, produziram uma grande surpresa na equipe de direção, e o efeito de espanto atingiu desta vez o comitê de acompanhamento. A visualização dos vídeos possibilitou aos membros dessa instância iniciar entre eles um diálogo sobre suas próprias atividades, a partir das dos agentes, pondo em prática a função social do coletivo (QUILLEROU, 2011). Esses artefatos vídeodialógicos tornaram-se instrumentos de outro diálogo entre os membros do comitê de acompanhamento, para considerar, a partir de iniciativas de campo reconstruídas pelos profissionais, transformações na organização do trabalho, se necessário. Aqui, o papel dos intervenientes é instituir uma atividade de "cooperação conflituosa" no seio desta instância (BONNEFOND, 2016; TRENTIN, 2012), atividade que, também para a equipe dirigente, é, naturalmente, fonte de inesperados "matizados de afetividade", em contato com um real muitas vezes "insignificante". Na condução das ACS e das ACC, bem como nos comitês de acompanhamento, o interveniente atua com essas mobilizações de afetividade.

\section{No comitê de acompanhamento: instituição da função social do coletivo de trabalho e mudanças de lugar}

Como observa Perrot (2019) em outro campo, buscando agir sobre os problemas concretos 'com' os profissionais e a gestão e não 'para' os profissionais, a direção, no comitê de acompanhamento, apresentou um novo ponto de vista sobre o métier e as maneiras de desenvolvê-lo. É neste sentido que se pode dizer que a intervenção não só levanta os problemas, mas desce a organização sobre os problemas. Melhor, segundo a autora, esses resultados foram provocados pelas mudanças de lugar do próprio interveniente. É esse movimento do interveniente nos diferentes registros do métier que ela designa como "atividade transferencial" (PERROT, 2017, 2019; SCHELLER, 2013) no diálogo e pelo diálogo e 'fisicamente' migrando pelos diferentes quadros da intervenção: a autoconfrontação cruzada e o comitê. Assim, o nomadismo do próprio interveniente sobre os registros do métier poderia favorecer, pelo menos em parte, o desenvolvimento do métier e a saúde dos profissionais.

Isso levanta a questão da função e do lugar do clínico na eficácia - ou não - da 
intervenção, quando se quer abordá-la menos em termos de risco do que em função dos recursos a promover - inclusive, organizacionais e "impessoais".

Mostraremos como tentamos fazê-lo antes do final da intervenção, com base em dois extratos do último comitê de acompanhamento, com profissionais da linha de frente engajadas na ação. Mostraremos a especificidade da apropriação do gênero de diálogo travado entre a hierarquia e o coletivo - com base nos resultados obtidos - antes mesmo da saída dos intervenientes, tratando assim do chamado "pós-CNAM" (Quadro 1).

Quadro 1: Último comitê de acompanhamento na presença dos agentes do grupo de trabalho do EPHAD, um momento de atividade transferencial

\begin{tabular}{|c|c|}
\hline \multicolumn{2}{|c|}{$\begin{array}{l}\text { Último comitê de acompanhamento na presença dos agentes do grupo de trabalho do EPHAD, um momento de } \\
\text { atividade transferencial }\end{array}$} \\
\hline Interveniente & $\begin{array}{l}\text { Enfim, acho que é preciso prever alguma coisa, continuar a refletir, desse ponto de vista, } \\
\text { todas as ideias são boas, né? é preciso prever alguma coisa, que as reuniões sobre o trabalho } \\
\text { possam acontecer, e não apenas quando a hierarquia tem um problema para resolver. (sorri) }\end{array}$ \\
\hline $\begin{array}{l}\text { Chefe do } \\
\text { estabelecimento }\end{array}$ & Não, mas é isso, é verdade que... \\
\hline Interveniente & $\begin{array}{l}\text { Penso que o importante é que reuniões sejam previstas, mesmo quando ainda não há } \\
\text { problemas a resolver, sabendo que haverá alguns e que, portanto, são reuniões cujo } \\
\text { conteúdo será feito por iniciativa das pessoas do campo, (os agentes) de vocês que se } \\
\text { preocupam com a qualidade, mesmo que depois, quando vão discutir entre vocês sobre a } \\
\text { qualidade, não estiverem necessariamente de acordo }\end{array}$ \\
\hline Agentes & (Leve agitação) \\
\hline Interveniente & A gente viu direito, estamos de acordo, né? \\
\hline Agente 2 & Exato, é isso que é interessante. \\
\hline Interveniente & $\begin{array}{l}\text { Isso é o que é interessante... Mas então, como construir, na organização, reuniões que } \\
\text { existem precisamente porque a iniciativa não pode vir apenas da hierarquia, esse é um ponto } \\
\text { extremamente importante. }\end{array}$ \\
\hline $\begin{array}{l}\text { Chefe do } \\
\text { estabelecimento }\end{array}$ & Hum, hum \\
\hline Interveniente & $\begin{array}{l}\text { E isto não é anti-hierárquico, porque permite à hierarquia ser mais concreta sobre questões } \\
\text { comuns... É isso que precisa chegar a... a iniciativa não pode vir apenas da direção, precisa } \\
\text { dirigir bem, né? }\end{array}$ \\
\hline $\begin{array}{l}\text { Chefe do } \\
\text { estabelecimento }\end{array}$ & Não, não, mas entendo bem. \\
\hline
\end{tabular}

Periódico Horizontes - USF - Itatiba, SP - Brasil - e021034 


\begin{tabular}{|c|c|}
\hline Interveniente & Porque eu não tenho nenhuma preocupação com o fato de que é preciso dirigir. \\
\hline $\begin{array}{l}\text { Chefe do } \\
\text { estabelecimento }\end{array}$ & $\begin{array}{l}\text { (dirigindo-se aos agentes) Isto é, deixar espaço para reuniões que teriam como tema } \\
\text { questões que preocupam vocês, e não apenas aquelas que nos preocupam... Não, mas eu } \\
\text { entendo. }\end{array}$ \\
\hline Interveniente & e que não vimos, porque onde estamos, não vemos. \\
\hline Diretora do polo & Mesmo se não tem um problema, é manter a reunião e é ir mais longe ... \\
\hline $\begin{array}{l}\text { Chefe do } \\
\text { estabelecimento }\end{array}$ & Hem \\
\hline Interveniente & $\begin{array}{l}\text { e que digam que a gente não tinha previsto discutir, mas agora é preciso discutir, e temos as } \\
\text { reuniões para isso, porque está previsto. }\end{array}$ \\
\hline $\begin{array}{l}\text { Chefe do } \\
\text { estabelecimento }\end{array}$ & $\begin{array}{l}\text { Não, não, mas é verdade que para nós é um..., para nós, está claro que uma direção é bem } \\
\text { normal, ela tem sua agenda. }\end{array}$ \\
\hline Interveniente & É uma questão de agenda. \\
\hline $\begin{array}{l}\text { Chefe do } \\
\text { estabelecimento }\end{array}$ & $\begin{array}{l}\text { De fato, e é prever, entre aspas, janelas vazias, ou espaço, ou tempo para coisas que estariam } \\
\text { na agenda, ou nas preocupações dos agentes, de modo a..., para as equipes... }\end{array}$ \\
\hline Interveniente & $\begin{array}{l}\text { Penso que a palavra agenda é muito boa, ou seja, quem decide sobre a agenda? Quem decide } \\
\text { colocar um problema na agenda? Porque, então, a agenda é também o prazo que damos um } \\
\text { ao outro para resolver o problema. Podemos concordar sobre o fato que tal problema é } \\
\text { preciso dois meses para resolvê-lo. Estamos de acordo. Depois disso, desde que não saia da } \\
\text { agenda, o problema pede para ser resolvido... Penso que pode ser muito simples, hein? }\end{array}$ \\
\hline $\begin{array}{l}\text { Chefe do } \\
\text { estabelecimento }\end{array}$ & Mas para que isso funcione, é preciso que cada um saiba o que tem que fazer. \\
\hline interveniente & $\begin{array}{l}\text { Essa é sua parte de definir o que cada um tem... enfim, quero dizer, é preciso inventar alguma } \\
\text { coisa, o controle hierárquico é importante, hein... mas, quem decide a agenda, isso é } \\
\text { importante... porque evidentemente como a gente dirige, a gente tem sempre a impressão } \\
\text { que é preciso que se decida a agenda dos problemas, só que têm problemas que não estão } \\
\text { na agenda daquele que dirige... É assim, né? é a realidade do trabalho... }\end{array}$ \\
\hline $\begin{array}{l}\text { Chefe do } \\
\text { estabelecimento }\end{array}$ & $\begin{array}{l}\text { Sim, de fato, o tema era aquele de depois da sua intervenção, mas isso mostra bem que há } \\
\text { alguma coisa em que trabalhar aí (movimentos de concordância com a cabeça). Para cada } \\
\text { parte... está claro... }\end{array}$ \\
\hline
\end{tabular}

Fonte: elaboração dos autores

O interveniente sugere à equipe de direção, na presença dos agentes, que as reuniões temáticas organizadas por sua iniciativa, embora tenham sua legitimidade, não podem ter o monopólio das trocas possíveis com os agentes. O chefe do estabelecimento é receptivo ao que ali se expressa. O interveniente, então, posicionando-se mais do ponto de vista dos agentes, lembra-Ihes de passagem que o diálogo em questão tem a ver com o que as profissionais Periódico Horizontes - USF - Itatiba, SP - Brasil - e021034 
praticaram durante as ACC. O debate construtivo sobre a qualidade do trabalho não tem o consenso como objetivo, embora seja uma boa maneira para mensurar os desafios do real. Nesse sentido, o que ainda não compartilhamos é mais interessante do que o que já compartilhamos.

Os agentes acolhem esta proposta, e o interveniente procura prosseguir. Dirige-se agora tanto ao chefe do estabelecimento como às profissionais: como construir reuniões que não sejam unicamente de origem hierárquica? Ao fazer isso, ele sugere não apenas que outra organização de reuniões seja possível, mas que a iniciativa possa vir de outro lugar, independemente da hierarquia.

O chefe do estabelecimento aprova com cautela e continua a refletir sobre o que foi apontado pelo interveniente algumas falas antes. Seremos sensíveis aqui às oscilações da postura do interveniente: percebendo o diálogo interior em curso do chefe do estabelecimento, ele se desloca novamente, para seu lado desta vez: "E isso não é anti-hierárquico", ele especifica para os representantes da hierarquia, mas também aos agentes e, ao fazê-lo, dá um passo adiante, especificando a natureza da abordagem que poderia ser considerada: "Isso permite à hierarquia ser mais concreta nas questões comuns...". Aqui encontramos a ideia de fazer "descer a organização até os problemas". Continuando e incentivando-o: "É isso que se deve conseguir ...". Esclarece a seguir a mudança de perspectiva: "A iniciativa não pode vir só da direção". Deste diálogo com várias vozes, o diretor ecoa: "Não, não, mas entendo bem". O interveniente, assumindo sua posição no registro impessoal da Direção, presta-se a suas perguntas, ao especificar que esta descida institucional ao real (PERROT, 2019) não visa "empurrar" as linhas hierárquicas, mas, ao contrário, apoiá-las: "Porque eu não tenho nenhuma preocupação com o fato de que é preciso dirigir". O chefe do estabelecimento, então, entra explicitamente no diálogo com essa espécie de "interveniente-homólogo". Ele reformula e se apropria da proposição que Ihe é feita: "é deixar espaço para reuniões que teriam como tema questões (aos agentes) que preocupam vocês e não apenas aquelas que nos preocupam... Não, mas eu entendo". O interveniente volta a se deslocar, coloca-se nos passos do diretor, mas acrescenta que cada parte tem os seus pontos cegos, e não só a direção: "que não vimos, porque lá onde estamos, não vemos". A diretora do polo então entra na troca: "Mesmo se não tem um problema, é manter a reunião e é ir mais longe ...". E justifica o seu interesse em ficar comprometida com o real. Depois 
que a importância de instituir espaços dedicados ao trabalho sobre o trabalho foi sublinhada pela diretora do polo e pelo interveniente, o diretor parece operar um ligeiro recuo, ao argumentar sobre a real carga de trabalho que pesa sobre a direção: "uma direção é normal, tem a sua agenda". O interveniente então se posiciona novamente do seu lado, e o diretor parece "pensar alto" com ele, considerando abrir sua agenda para novas questões: "é prever, entre aspas, janelas vazias, ou espaço, ou tempo para coisas que estariam na agenda, ou nas preocupações dos agentes, de modo $a$, das equipes...". O interveniente dá mais um passo nessa direção: não se trata apenas de "deixar uma espaço vazio" na agenda, mas de saber quem preenche o conteúdo: "Quem decide colocar um problema na agenda?" A diretora do polo, certamente preocupada com o que está surgindo, dirige-se ao seu diretor e a suas colaboradoras, e lembra que cada um tem prerrogativas diferentes. $O$ interveniente fortalece seu lugar e suas funções habituais: "o controle hierárquico é importante, hein? ...", ao mesmo tempo que insiste sobre os conflitos de agenda aos quais não está habituada: "como dirigimos, sempre temos a impressão de que temos de decidir sobre a agenda dos problemas, só que há problemas que não estão na agenda daquele que dirige. É assim hein, é a realidade do trabalho...".

No final da reunião, o chefe do estabelecimento indica seu interesse em continuar a intervenção, de uma nova forma, e tranquiliza sua adjunta: "Sim, por enquanto, o tema era aquele de depois da sua intervenção, mas isso mostra bem que há alguma coisa em que trabalhar aí (movimentos de concordância com a cabeça). Para cada parte... está claro...".

Através dos deslocamentos que faz nos diferentes registros do métier, o interveniente participa também da apropriação, pelas diferentes partes, da natureza do diálogo que se troca e que permanece centrado sobre o real da atividade e sobre a construção coletiva de soluções nas quais ninguém teria pensado sozinho.

\section{O segundo dispositivo de intervenção: "instituição de uma controvérsia social sobre o trabalho bem-feito" em diferentes níveis hierárquicos}

No final desta primeira ação, as profissionais, que, por sua forma de dominar seu trabalho, tornaram- se interlocutoras de referência para a direção, demonstram o desejo de 
continuar o trabalho iniciado com os intervenientes. A linha hierárquica, tranquilizada e encorajada pela qualidade dos diálogos realizados no comitê de acompanhamento, apoia o seu pedido e acrescenta outro: ser, ela mesma, acompanhada na instituição de espaços de diálogo centrados na definição da qualidade do trabalho - tanto o seu próprio como o dos agentes.

No prolongamento deste comitê de acompanhamento, a forma que poderia assumir essa continuação foi objeto de deliberações no seio dos dois coletivos associados: com a direção e com os sindicatos. Foi durante essas trocas que os agentes evocaram a possibilidade de os profissionais de referência poderem representá-los, para continuar os diálogos iniciados com a direção em novos espaços, previstos para este fim.

Foi assim que a direção quis orientar a sua nova comanda para criar um dispositivo centrado na organização do trabalho no seio de cada uma dessas unidades.

Uma segunda convenção, desta vez financiada apenas pelo estabelecimento, visará a implementação de um "desenvolvimento do diálogo sobre a qualidade do trabalho". Ela prevê instituir uma controvérsia social sobre o trabalho bem-feito, com vista a desenvolver a saúde e a eficiência no trabalho. Trata-se de conceber e implementar este novo dispositivo.

Nesta perspectiva, um novo dispositivo será coconstruído com a direção, validado pelas organizações sindicais e depois apresentado à gestão e aos agentes envolvidos para seu parecer também.

Isso envolve três níveis de ação:

- o serviço, com a criação de profissionais de referência (RM);

- o polo, no seio de uma Instância de Diálogo sobre o Métier (IDM);

- o estabelecimento, com a constituição de um Comitê de estabelecimento (CE).

Especificamos abaixo o funcionamento deste dispositivo que se inspira naqueles que foram implantados noutros locais (BONNEFOND, 2016 ; BONNEMAIN, 2019).

\section{No campo, as profissionais de referência: instituição da função do coletivo de trabalho como meio de ação na organização}

No nível de cada um dos serviços, as profissionais de referência emergiram dos coletivos 
de trabalho formados durante a primeira ação. Nesta nova posição, elas instituem a função do coletivo de trabalho como meio de ação na organização. Como vimos, foi durante os comitês de acompanhamento da primeira ação que foram construídas as condições para que essas profissionais contribuam para o diálogo com a hierarquia e os sindicatos sobre o trabalho real. Esta mudança de posição e de função conferiu-lhes uma responsabilidade diferente da que possuíam na fase de análise da sua atividade.

Quatro profissionais de referência por polo são designadas pelos membros do coletivo para um mandato de seis meses, renovável. Elas incorporam, assim, uma autoridade profissional nova, legitimada pelos seus pares. São encarregadas de coletar os problemas entre os colegas e de instruí-los a respeito deles. Trata-se dos impedimentos com os quais se confrontam em campo para realizarem o seu trabalho com os residentes. Nenhuma ilusão pode ser mantida: o trabalho não é "transparente" nem inteiramente acessível aos próprios agentes; os problemas concretos que estes profissionais identificam são apenas uma porta de entrada para questões mais complexas do que o previsto, que envolvem os diferentes destinatários da sua atividade.

De maneira sistemática, quando um problema é coletado, é passado pelo crivo de uma análise coletiva, e as profissionais de referência questionam os seus colegas e debatem com eles as soluções possíveis para resolvê-lo. Essas trocas ocorrem durante o trabalho normal. Por outro lado, é-Ihes concedido um tempo dedicado e incluído no calendário (meio dia por mês) para permitir que se reúnam, façam um inventário dos problemas coletados e estabeleçam a hierarquia de prioridades. As dificuldades coletadas e as soluções previstas são listadas em uma "Tabela Comum de Problemas" (TCP), (cf. Quadro 2). Essa matriz foi desenhada pelas profissionais de referência com o interveniente e validada durante o primeiro IDM. Ali estão declinadas, de acordo com diferentes critérios, temáticas evolutivas qualificadas por estes agentes: Recursos humanos, Funcionamento da equipe ... (conforme se indica abaixo).

Esses problemas e a ordem de prioridade proposta pelas profissionais de referência são então discutidos com sua gestão local. Aqueles que não puderam ser resolvidos em seu nível são dirigidos à "Instância de Diálogo sobre o Métier".

Periódico Horizontes - USF - Itatiba, SP - Brasil - e021034 


\section{No nível do polo, criação de uma instância de diálogo sobre o métier (IDM): multiplicar as objeções para encontrar soluções em conjunto}

Uma IDM por polo é criada. Duas profissionais de referência são nomeadas por seus colegas para participar dela e assegurar a continuação das soluções que lá serão observadas. A IDM reúne, em torno da diretora do polo: o diretor de $\mathrm{RH}$, a gestão de saúde, as organizações sindicais, as funções suportes, duas profissionais de referência e os intervenientes. A IDM se reúne a cada dois meses. O papel dos intervenientes inclui dar suporte à instituição de um diálogo sobre a qualidade do trabalho a partir desses diferentes pontos de vista, experimentando as virtudes do conflito de critérios ao longo do tempo e também acompanhar a coconstrução de soluções nas quais ninguém havia pensado sozinho. Assim como durante as ACC ou nos comitês de acompanhamento da primeira ação, os intervenientes conservam na IDM a mesma postura profissional, que consiste em se deslocar entre os diferentes registros do métier, identificar e pôr em diálogo não mais só as diferenças na maneira de atuação dos agentes, mas também as diferenças de pontos de vista adotados sobre a qualidade do serviço prestado ao residente.

Diferentes problemas concretos, provenientes de registros diferentes, puderam ser tratados: gestão dos cronogramas, repartição dos recursos humanos, aquisição de material adaptado, organização dos locais, consistência e temperatura das refeições, definição de cuidado, de um lugar de vida, utilidade de uma vestimenta profissional...

A página seguinte, relativa à temática "Recursos humanos", foi retirada de um TCP apresentado em IDM durante a intervenção. Nela aparecem as diferentes rubricas abordadas. Aqui estão expostas de maneira concreta as questões que revelam, na atividade habitualmente exercida por agentes experientes, sua substituição, durante as férias de verão, por pessoas pouco ou nada experientes. Aparecem igualmente as soluções propostas e finalmente adotadas após a discussão.

A problemática levantada pela iniciativa dos agentes está relacionada com suas consequências sobre a qualidade dos cuidados ao residente. Vemos que a preocupação dos agentes é dupla: ela tem a ver com a segurança dos residentes. De fato, confiar aos substitutos 
iniciantes, ou "amadores", o cuidado de alimentar pessoas idosas ou acometidas de deficiência pesada pode colocar suas vidas em perigo - o engasgar é muitas vezes fatal em pessoas dependentes. Tem também a ver com a responsabilidade profissional dos agentes experientes que pode ficar comprometida em caso de acidente.

Quadro 2: Uma página do Quadro de Problemas Comuns, preenchido pelos agentes: instrumento do diálogo em IDM

\begin{tabular}{|c|c|c|c|c|c|c|c|}
\hline Problemáticas & Consequências & $\begin{array}{l}\text { Soluções } \\
\text { propostas }\end{array}$ & $\begin{array}{l}\text { Soluções } \\
\text { adotadas }\end{array}$ & $\begin{array}{l}\text { Data de } \\
\text { validação }\end{array}$ & Prazo & Avanços & Avaliação \\
\hline $\begin{array}{l}\text { Substitutos de } \\
\text { verão } \\
\text { Responsabilidade } \\
\text { do titular }\end{array}$ & $\begin{array}{c}\text { Risco/ } \\
\text { eventualidade } \\
\text { de insegurança } \\
\text { para o residente } \\
\text { (engasgo) = } \\
\text { (podendo ser } \\
\text { situações de } \\
\text { ansiedade) }\end{array}$ & $\begin{array}{c}\text { Privilegiar os } \\
\text { candidatos } \\
\text { diplomados } \\
\text { ou antigos } \\
\text { estagiários } \\
\text { tendo um } \\
\text { bom } \\
\text { conhecimento } \\
\text { dos } \\
\text { residentes. } \\
\text { Estabelecer } \\
\text { estatísticas } \\
\text { para definir as } \\
\text { necessidades } \\
\text { e a duração } \\
\text { das } \\
\text { substituições }\end{array}$ & $\begin{array}{l}\text { Constituição } \\
\text { de uma } \\
\text { reserva de } \\
\text { estagiários } \\
\text { substitutos, } \\
\text { integrar o } \\
\text { pessoal mais } \\
\text { qualificado } \\
\text { com contratos } \\
\text { mais longos; } \\
\text { difundir a } \\
\text { informação } \\
\text { nas escolas } \\
\text { IDE } / \text { AS para o } \\
\text { recrutamento }\end{array}$ & $\begin{array}{c}27 \text { de abril } \\
\text { de } 2017 \\
\text { outono } \\
2016\end{array}$ & $\begin{array}{c}\text { verão } \\
2017\end{array}$ & $\begin{array}{l}\text { Em curso: } \\
\text { reunião em } 8 \\
\text { de março de } \\
\text { 2017: envio a } \\
\text { cada IFSI }^{7} \text { de } \\
\text { um perfil de } \\
\text { posto + rede } \\
\text { CHU }^{8} \\
\text { relançada pela } \\
\text { DRH para as } \\
\text { necessidades } \\
\text { do polo de } \\
\text { adultos } \\
\text { deficientes }\end{array}$ & \\
\hline
\end{tabular}

Fonte: elaboração dos autores

Como indicado mais acima, as soluções propostas na IDM são aquelas que não encontraram resposta no diálogo com chefia imediata. As "soluções adotadas" o são após discussão na IDM. Elas podem seguir, prolongar, como é o caso no exemplo acima, ou propor outras vias diferentes daquelas previamente pensadas com a gestão de saúde. Um "prazo" para implementação da solução adotada é proposto na IDM e é objeto de um acompanhamento de seu "avanço". Esta abordagem, induzida pelo uso do artefato singular do Quadro informatizado concebido com as profissionais de referência, é a que lhes demandará maior esforço de

\footnotetext{
${ }^{6}$ Enfermeiro(a) diplomado(a) do Estado

${ }^{7}$ Instituto de Formação em Cuidados de Enfermagem

${ }^{8}$ Centro Hospitalar Universitário
} 
apropriação, justificando plenamente uma "clínica do uso" (BOBILLIER-CHAUMON; BARVILLE; CROUZAT, 2019). As soluções adotadas são avaliadas em seguida, e a apreciação feita delas é escrita na coluna prevista para esse efeito.

Fornecemos agora um exemplo de diálogo conduzido durante uma das últimas IDM na presença de um diretor em formação, que assegurará a substituição da diretora do Polo em licença-maternidade durante esta segunda ação. Escolhemos este "excerto" um pouco longo, em razão da intensidade do conflito de critérios que se desenvolve e dos afetos que ele provoca (Quadro 3).

O fato de que as RM se tornam suas interlocutoras de referência conduz a direção a aumentar o nível de exigência de seu próprio trabalho, como sublinhará o futuro diretor do estabelecimento: "Quanto mais eu trabalho com vocês, mais eu necessito discutir com a gestão de saúde, com minhas colegas diretoras de polo, DRH, mais eu necessito discutir com o diretor".

\section{No nível do estabelecimento, constituição de um comitê de estabelecimento: um garantidor da intervenção do lado da direção e sindicatos}

Os problemas transversais no conjunto dos serviços e que ultrapassam então o perímetro do polo são dirigidos ao comitê de estabelecimento (CE) para apreciação e decisão. Este último, presidido pelo chefe de estabelecimento, reagrupa a equipe de direção, a gestão, as organizações sindicais e os intervenientes. Reuniu-se três vezes.

O CE é também o garantidor do bom funcionamento deste novo dispositivo. Seus membros, por exemplo, foram solicitados a contribuir para sair de uma crise que atingiu o IDM do polo gerontologia, no qual as profissionais de referência deixaram o dispositivo em razão de sua insuficiente produtividade do momento. Para trazer de volta as interessadas, foi preciso que as diferentes partes mobilizassem as aprendizagens realizadas a partir do conflito dialógico.

A organização deste novo dispositivo conduziu a novas arbitragens organizacionais que foram fonte de saúde. Entretanto, uma dificuldade permanece: mesmo se a organização do trabalho muda na nossa presença, o "exame livre" solicitado por essas novas instituições não está garantido de uma vez por todas.

Periódico Horizontes - USF - Itatiba, SP - Brasil - e021034 
A ideia é justamente assegurar a perenização da iniciativa retomada pelos profissionais após o 'andaime' da nossa intervenção ter sido retirado, quando deixamos a organização. Se a organização do trabalho não mudou na nossa presença, se a cooperação conflituosa entre assalariados, sindicatos e hierarquia que experimentamos com eles não pode ser verdadeiramente instituída, há um risco - sempre presente, sempre funcionando - de que as liberdades profissionais reconquistadas retrocedam de novo (CLOT et. al., 2016, p.3).

Após nossa saída, o CE foi substituído por uma "instância tripartite", prevista para reunir, em torno do diretor, a equipe de direção e de gestão, as organizações sindicais e - coisa inédita - uma profissional de referência de cada um dos polos. A designação destas últimas foi discutida entre profissionais de referência e com as diretoras e as gestões de saúde dos polos concernidos. As IDM sobre elas funcionaram e continuam funcionando na nossa ausência.

Uma terceira convenção teve início. Ela se inscreve no quadro de uma chamada de projetos da ARS Normandie. Seu objeto é a generalização deste dispositivo aos AS e aos AMP do conjunto de serviços do estabelecimento.

Quadro 3: Excerto de diálogo na última IDM: um momento de "cooperação conflituosa"

\begin{tabular}{|l|l|}
\hline Aluno diretor (ED) & $\begin{array}{l}\text { Para mim, fizemos uma forma de curva de aprendizagem, quer dizer, ao longo das IDM } \\
\text { podemos tratar dos problemas sem que isso seja (bate com o punho na mão) no conflito } \\
\text { ou em oposição... (às RM), quer dizer que vocês nos trazem as coisas para as quais é } \\
\text { preciso que tomemos as medidas, pois nossas referências não são as mesmas... enfim, } \\
\text { eu o que eu penso é que, quando vocês levantam as coisas sobre a dificuldade de } \\
\text { acompanhamento, claro que a gente objetiva, e depois a gente reflete (aponta com seus } \\
\text { dedos) com a equipe de direção, com o médico coordenador nas instâncias entre nós, } \\
\text { porque nós também, a gente precisa dialogar, quer dizer que suas necessidades de } \\
\text { diálogo, eu estimo que eu tenho ainda mais necessidade... quer dizer que mais eu falo } \\
\text { com vocês, mas eu preciso falar com o DRH, mais eu preciso falar com a diretora de } \\
\text { polo, com o diretor do estabelecimento, mais eu preciso falar com o conjunto da equipe } \\
\text { de gestão para melhor compreender a realidade do acompanhamento dos residentes. }\end{array}$ \\
\hline $\begin{array}{l}\text { Profissional } \\
\text { referência 1 (RRM) de }\end{array}$ & $\begin{array}{l}\text { Sim, eu te entendo bem, mas ao mesmo tempo (vira-se para a colega) ao mesmo tempo, } \\
\text { eu tenho 15 anos de serviço e eu nunca dialoguei tanto, enfim, eu nunca tinha (insiste e } \\
\text { olha o DRH) dialogado (emoção na voz) com a hierarquia, é a primeira vez enfim... (olha } \\
\text { os intervenientes e o ED). Não, mas... }\end{array}$ \\
\hline ED & \begin{tabular}{l} 
Mas você tem razão é importante de dizer. \\
\hline
\end{tabular} \\
\hline
\end{tabular}

Periódico Horizontes - USF - Itatiba, SP - Brasil - e021034 


\begin{tabular}{|c|c|}
\hline Interveniente & $\begin{array}{l}\text { Posso dar minha pitada lá? (olha as RRM e a equipe de direção) então aqui é um } \\
\text { problema que temos na discussão que é muito importante... porque por quê (para a } \\
\text { direção) vocês, vocês estão tendo uma experiência que eu compreendo bem, porque se } \\
\text { alguém me dirigir um texto no qual eu sou tratado de incoerente }{ }^{9} \text { (sorrisos de RRM1) } \\
\text { isso mexe comigo, né? mas eu penso que é necessário que vocês meçam, inversamente, } \\
\text { até que ponto, o que parece a vocês na linguagem da gestão é: uso do número, o que } \\
\text { parece perfeitamente racional. }\end{array}$ \\
\hline $\begin{array}{l}\text { DRH: (opina ao chefe e } \\
\text { sorri) }\end{array}$ & É interessante. \\
\hline Interveniente & $\begin{array}{l}\text { Certo? bem do ponto de vista delas (designa as RRM) isto choca com a experiência das } \\
\text { realidades vividas (silêncio)... então, o que você experimenta aí. (ao ED) você diz, eu } \\
\text { também eu sou afetivo, felizmente né? é preciso mensurar que o inverso existiu e talvez } \\
\text { durante } 15 \text { anos (olha RRM1). }\end{array}$ \\
\hline RRM1 & Bom, sim, mas... \\
\hline ED & $\begin{array}{l}\text { É por isso que eu aprecio quando RRM2 nos diz que atrás, os números, eles não querem } \\
\text { dizer grande coisa... Acho que admitimos isso. }\end{array}$ \\
\hline Interveniente & $\begin{array}{l}\text { Aí existe uma experiência comum que é feita, sobre, como direi, a violência que pode } \\
\text { passar pelas palavras. }\end{array}$ \\
\hline ED & Pelos números. \\
\hline Interveniente & $\begin{array}{l}\text { Pelos números, isto, pelos números e eu penso que essa experiência, ela é extremamente } \\
\text { importante para todos [...]. }\end{array}$ \\
\hline Interveniente & $\begin{array}{l}\text { Para saber como vocês farão quando a gente estiver indo embora, precisamos tentar } \\
\text { entender a que a gente serviu?... eu queria propor a questão a todos.... Se vocês } \\
\text { precisarem dizer coisas assim uns aos outros?... se a gente for embora, para conservar } \\
\text { os benefícios, é preciso saber para que servimos quando a gente for embora... é útil para } \\
\text { nós também, diga-se de passagem. }\end{array}$ \\
\hline RRM1 & $\begin{array}{l}\text { Ah, eu diria, para amarrar o diálogo, pois não havia diálogo... também, para nos dar } \\
\text { novamente confiança... (vira-se para a colega e continua virada para ela) porque a gente } \\
\text { estava... (emoção na voz) é difícil... a gente era uma equipe... em dificuldade... } \\
\text { (lágrimas)... }\end{array}$ \\
\hline RRM2 & $\begin{array}{l}\text { E também é.... vocês conseguiram colocar os fundamentos, e agora nos permitem } \\
\text { continuar }\end{array}$ \\
\hline ED & os fundamentos do diálogo? \\
\hline
\end{tabular}

\footnotetext{
${ }^{9}$ Em uma fala precedente, o aluno diretor interpela as profissionais de referência sobre um email a ele dirigido no qual elas escrevem que uma "incoerência reina" nas decisões em curso.
}

Periódico Horizontes - USF - Itatiba, SP - Brasil - e021034 


\begin{tabular}{|l|l|}
\hline RRM2 & Sim. \\
\hline ED & $\begin{array}{l}\text { Para mim, o que eu guardo deste dispositivo é a maneira como ele vive... quer dizer que } \\
\text { a gente teve através destas IDM tempos de troca com os parceiros sociais, com os } \\
\text { colegas do serviço de apoio, a direção de recursos humanos.... para mim, isto me ensinou } \\
\text { a olhar diferentemente... a realidade do trabalho do outro.... quer dizer a maneira como } \\
\text { vocês fizeram levantar o trabalho de vocês... como dizer? Tenho a impressão de que o } \\
\text { que eu projetava de acompanhamento de um residente, do que era possível, bem, talvez } \\
\text { a gente compartilhasse talvez os mesmos valores, mas os valores isso não é suficiente, } \\
\text { a gente compartilha os mesmos, no final era necessário compartilhar a realidade do que } \\
\text { a gente espera das coisas do que era possível para uns e para os outros.... e que no } \\
\text { mínimo tratamos as coisas... e que a gente acompanha também... inclusive nas } \\
\text { dificuldades que encontramos... o diálogo deve ser mantido, qual dinâmica isso toma? } \\
\text { eu achei isso extremamente fundamental. }\end{array}$ \\
\hline
\end{tabular}

Fonte: elaboração dos autores

\section{Discussão}

Podemos compartilhar a ideia de que a intervenção deve alimentar uma confrontação psicossocial favorável para a maturação da organização das questões de saúde psíquica no trabalho. A intervenção é, mesmo, a ocasião de influenciar o nível de maturidade de uma organização sobre essas questões (ROUAT, 2010).

Detchessahar (2019), sem contradizer este ponto de vista, fez, de seu lado, da existência de espaços de discussão um critério central desta maturidade. Retomando a ideia de "empresa deliberada" (CLOT; LALLEMENT, 2015, p.52), contra as ambiguidades anti-hierárquicas da "empresa liberada" (DETCHESSAHAR, 2019; UGHETTO, 2018), insistiu sobre a importância do lugar a ser atribuído ao nível de decisão, para poder vislumbrar uma transformação da organização do trabalho. Para isso, propõe colocar a animação desses espaços coletivos sob a autoridade exclusiva da própria gestão. Podemos discutir esse ponto de vista à luz da intervenção apresentada aqui. Partilhamos a preocupação de vincular a elaboração concreta dos coletivos de trabalho às decisões organizacionais cuja responsabilidade cabe às direções. Os coletivos de métier sempre correm o risco de fechar-se, se não corresponderem às restrições organizacionais. E o gênero profissional é somente um recurso transpessoal sustentável do métier, se for traduzido - no sentido forte - no registro impessoal da organização.

Mas o que permite sustentar o exemplo analisado acima é que a linha hierárquica não 
perde nada - se é a preocupação com a eficiência que a orienta -, ao instituir a iniciativa dos agentes "de campo" na agenda organizacional. Ao renunciar ao seu monopólio nesta agenda, permite, em primeiro lugar, às profissionais que estão na 'vanguarda' da qualidade do trabalho tornarem-se, primeiramente entre si, "forças de lembrança": não para fazer subir os problemas para serem resolvidos, mas para fazer descer a organização para as soluções circunstanciadas possíveis para esses problemas. Mas também permite aos agentes "de campo" beneficiar-se, em contrapartida, das objeções apreendidas pela linha hierárquica, para desenvolver ainda o trabalho de organização do coletivo pela mediação das profissionais de referência. 0 poder de agir em conjunto é a chave para essa animação recíproca da discussão sobre o trabalho, da qual nenhuma das partes interessadas pode ter o privilégio discricionário, mesmo que a decisão final permaneça uma prerrogativa da direção (CLOT, 2019). Esse resultado alimenta as recentes conclusões de trabalhos em ergonomia (DOMETTE, 2019).

Podemos constatá-lo, como destacam Detchessahar (2019), Rouat e Sarnin (2019), embora este tipo de intervenção seja um objeto de pesquisa mais recente (CLOT; QUILLEROU-GRIVOT, 2014; MIOSSEC; CLOT; BOUCHER, 2014), nos trabalhos em clínica da atividade que prestam atenção elevada ao nível de tomada de decisão, para deslocar os problemas levantados na análise dos conflitos da atividade na direção do problema dos conceptores e dos gestores (BONNEFOND, 2016, 2017; BONNEMAIN, 2015; CLOT; SIMONET, 2015; ZITTOUN; LARCHEVEQUE, 2018).

\section{Conclusão}

Por hora, encerraremos concluindo sobre os obstáculos que qualquer intervenção deste tipo encontra. Salientar, por exemplo, que este novo esquema de ação não pretende "quebrar" as linhas hierárquicas nem as prerrogativas sindicais não é suficiente para tranquilizar os principais interessados. Assim, se a questão do voluntariado está, por exemplo, ganha para os agentes de campo, deve ser abordada com lucidez para a chefia imediata. Esta última, na maioria das vezes, não tem outra escolha senão seguir a decisão de sua direção geral de se engajar neste tipo de ação, seja qual for sua opinião. Esses gestores podem até ter a impressão de que "precisam prestar contas a seus agentes". Precauções maiores são necessárias, então, neste 
ponto, que implica um trabalho clínico dedicado, antes e durante a intervenção, para lhes permitir igualmente construir coletivamente os recursos próprios neste novo dispositivo. No que diz respeito aos sindicatos, definir o perímetro de ação entre as organizações sindicais e as profissionais de referência se mostrou um ponto importante a ser discutido. $O$ dispositivo implementado não tem como vocação retirar qualquer atribuição dos representantes do pessoal. Mas, afora algumas experiências inéditas (REMERMIER; CARDOSO, 2018; ROGER, 2007), o sindicalismo dificilmente se concentra no conteúdo do trabalho, e defender as condições de trabalho não equivale a se responsabilizar concretamente pelo desenvolvimento dos gestos do métier (BRIEC, 2014). É precisamente o papel dos profissionais de referência instrumentar o sindicalismo nesta matéria, se assim o desejar.

Diante da profundidade das questões levantadas por esse questionamento da divisão clássica do trabalho, esse modelo é desconcertante para todas as partes interessadas. É, pois, importante que um garantidor do funcionamento "regulado" do dispositivo seja instituído no seio de uma instância tripartite (entre direção, profissionais de referência e sindicatos), sendo a função dos intervenientes, como garantidores externos, apenas transitória. A "fabricação da organização do trabalho" a que esta abordagem visa não pode substituir a organização do trabalho existente. Ela a questiona, mas pode ser vista como uma contribuição a um trabalho vivo da organização. Finalmente, outra vigilância é necessária do lado das profissionais de referência. Essas profissionais trocam de lugar e, ao fazê-lo, assumem responsabilidades bem distintas da análise da própria atividade. Ser autoridade na organização ao lado tanto da hierarquia quanto dos colegas é custoso e pode "desgastar" as pessoas. Corre-se o risco de banalizar a energia que este tipo de deslocamento requer. A presença muito regular do interveniente no campo, mesmo quando ele tem que se preparar para sua saída, é, portanto, um ponto nodal do sistema, sobretudo neste ambiente.

Em suma, portanto, só podemos avançar neste caminho organizando uma comparação sistemática e sem complacência das experiências atuais e futuras. Este é um programa de pesquisas capaz de, por si só, documentar a relevância dos vínculos estabelecidos no início deste artigo entre saúde e eficácia. As variações nesse estilo de intervenções em clínica da atividade são objetos valiosos de análise. Por fim, vamo-nos permitir os riscos de um inventário: essas 
variações se devem a situações diferentes inicialmente. Uma fábrica de automóveis de vários milhares de pessoas apresentando um dispositivo de uma centena de operários de referência eleitos por seus pares em cada linha de montagem (BONNEFOND, 2019) difere das equipes de um EPHAD, na qual as profissionais de referência foram designadas por seus colegas sem eleições formais. E, ainda que os catadores de lixo da cidade onde se realizou o experimento descrito por A. Bonnemain (2019) tivessem, de fato, elegido seus profissionais de referência, a proximidade de pequenas equipes instala de imediato, entre esses profissionais de referência, um conhecimento que será somente adquirido no longo prazo, na fábrica de automóveis. A atividade realizada (cuidado de pessoas dependentes, limpeza urbana e produção industrial) também separa essas intervenções, não só pelo objeto, mas também pelos destinatários dessa atividade: as famílias dos residentes estão presentes nos trabalhos do EPHAD de forma diferente dos clientes da produção de automóveis ou, mesmo, como usuários também eleitores de um município. A história original do "diálogo social" em cada campo também o torna incomparável a outro: os representantes sindicais estão presentes aqui em cada IDM e na CE. Para o serviço municipal de limpeza, eles estão presentes apenas no nível da segunda instância de acompanhamento, sem participar diretamente do diálogo de primeiro nível; na fábrica em questão, sua presença também se concentra em uma instância tripartite, encarregada de "monitorar" o dispositivo. No final, essa diversidade é constitutiva de uma metodologia de desenvolvimento ad hoc, em que o método dos profissionais de referência se singulariza a cada vez. E, a cada vez também, em função da experiência clínica própria dos intervenientes. Este artigo é, em si, uma matéria-prima para o estudo dessas variações.

\section{Referências}

BAKHTINE, M. Pour une philosophie de l'acte. Lausanne: L'Age d'Homme, 2003.

BOBILLIER-CHAUMON, M. E.; BARVILLE, N.; CROUZAT, P. Les technologies émergentes au travail: quel apport de la psychologie du travail et des organisations? Le Journal des psychologues, v.5, n.367, p.16-21, 2019.

BONNEFOND, J.-Y. L'intervention dans l'organisation en clinique de l'activité. Le dispositif "DQT" à l'usine Renault de Flins. 2016. 285f. Thèse (Doctorat en Psychologie) - Cnam, Paris, 2016. 
BONNEFOND, J.-Y. Intervention et développement organisationnel en clinique de l'activité. Activités, v.14, n.2, p.1-28, 2017. Disponível em: https://journals.openedition.org/activites/3014. Acesso em: 01 jun. 2021.

BONNEFOND, J. Y. Agir sur la qualité du travail: I'expérience de Renault Flins. Toulouse: Erès, 2019.

BONNEMAIN, A. Les paradoxes de l'intensité affective dans l'autoconfrontation: I'exemple de l'activité dialogique des chefs d'équipe de la propreté de Paris. 2015. 315f. Thèse (Doctorat en Psychologie) - Cnam, Paris, 2015.

BONNEMAIN, A. Affect et comparaison dans le dialogue en autoconfrontation. Activités, v.16, n.1, p.1-33, 2019. Disponível em: https://journals.openedition.org/activites/1120. Acesso em: 01 jun. 2021

BRIEC, C. L'activité syndicale: un travail ordinaire? Nouvelle Revue de Psychosociologie, n.18, p.69-83, 2014.

CANGUILHEM, G. Résistance philosophie biologique et histoire des sciences: œuvres complètes (tome IV). Paris: Vrin, 2015.

CHAMBON, N.; PICHON, A. Supporter le travail de la relation? Rhizome, n.67, p.5-11, 2018.

CLOT, Y. Travail et pouvoir d'agir. Paris: PUF, 2008.

CLOT, Y. et. al. Questions autour de la clinique de l'activité. Nouvelle Revue du Travail, n.9, p.19, 2016. Disponível em: http://journals.openedition.org/nrt/2900. Acesso em: 01 jun. 2021.

CLOT, Y. L'affectivité en activité. In: BARBIER, J.-M.; DURAND, M. (ed.). Encyclopédie d'analyse des activités. Paris: PUF, 2017. p.887-920.

CLOT, Y. Préface - “dialoguer pour faire autorité". In: DETCHESSAHAR, M. (coord). L'entreprise delibérée: refonder le management par le dialogue. Bruyères-le-Châtel: Nouvelle cité, p.7-19, 2019.

CLOT, Y. et al. Les entretiens en auto-confrontation croisée: une mé thode en clinique de I'activité. Éducation permanente, n.146, 17-27, 2001.

CLOT, Y.; LALLEMENT, M. Qualite' de vie au travail/qualité du travail? Revue sur les Conditions de Travail, n.3, p.46-56, 2015.

CLOT, Y.; QUILLEROU-GRIVOT, E. La qualité du travail, un problème avant d'être une solution. In: LHUILLIER, D. (ed.). Qualité du travail, qualité au travail. Toulouse: Érès, 2014. 
CLOT, Y.; SIMONET, P. Pouvoirs d'agir et marges de manœuvre. Le Travail Humain, v.1, n.78, p.31-52, 2015.

DETCHESSAHAR, M. (coord). L'entreprise délibérée: Refonder le management par le dialogue. Bruyères-le-Châtel: Nouvelle cité, 2019.

DOMETTE, L. La conception pour et dans l'usage de dispositifs de discussion sur le travail. 2019. 347f. Thèse (Doctorat en Ergonomie) - Cnam, Paris, 2019.

DUBOSCQ, J.; CLOT, Y. L'autoconfrontation croisée comme instrument d'action au travers du dialogue: objets, adresses et gestes renouvelés. Revue d'Anthropologie des Connaissances, n.2, p.255-286, 2010.

FERNANDEZ, G. Soigner le travail. Toulouse: Érès, 2008.

FERNANDEZ, G. et al. Nous, conducteurs de trains. Paris: La Dispute, 2003.

KOSTULSKI, K. et al. L'horizon incertain de la transformation en clinique de l'activité. Activités, v.8, n.1, p.129-145, 2011. Disponível em: http://journals.openedition.org/activites/2456. Acesso em: 01 jun. 2021

MIOSSEC, Y. et al. Le développement du collectif: un moyen durable de prévention de la santé au travail? Nouvelle Revue de Psychosociologie, v.10, n.1, p.194-208, 2010.

MIOSSEC, Y.; CLOT, Y. Le métier comme instrument de protection contre les risques psychosociaux: le cas d'ingénieurs managers de proximité. Le Travail Humain, v.4, n.74, p.341363, 2011.

MIOSSEC, Y.; CLOT, Y.; BOUCHER, C. L'intervention dialogique pour agir sur les risques psychosociaux: une troisie` me voie. In: LEROUGE, L. (ed.). Approche interdisciplinaire des risques psychosociaux au travail. Toulouse: Octarès, 2014. p.51-66.

PERROT, E. L'activité transférentielle, une ressource au service du développement du métier: le cas des agents d'escale et de service commercial en gare. 2017. 290f. Thèse (Doctorat de Psychologie) - Cnam, Paris, 2017.

PERROT, E. Le métier, levier de prévention des risques psychosociaux? Raison Présente, n.209, p.79-88, 2019.

POUSSIN, N. Développement des sentiments au travail: dialogues sur l'efficacité et l'utilité chez les médecins du travail. 2014. 236f. Thèse (Doctorat de Psychologie) - Cnam, Paris, 2014. 
QUILLEROU, E. Fonction psychologique et sociale du collectif pour la santé au travail: le cas de l'activité d'opérateurs de montage automobile. 2011. 261f. Thèse (Doctorat en Psychologie) Cnam, Paris, 2011.

QUILLEROU, E.; CLOT, Y. Trois conditions pour une clinique de l'activité en psychologie du travail: le cas d'une intervention dans une entreprise de logistique automobile. Activités, v.10, n.2, p.229-248, 2013. Disponível em: https://journals.openedition.org/activites/842. Acesso em: 01 jun. 2021.

REILLE-BAUDRIN, E.; ZITTOUN, M. Meurtre de deux inspecteurs du travail dans l'exercice de leur métier: re-trouver l'événement pour sortir de l'angoisse. Nouvelle Revue de Psychosociologie, v.19, n.1, p.65-78, 2015.

REMERMIER, C.; CARDOSO, A. Prendre soin du travail, une exigence pour l'activité syndicale et la défense des métiers. Agone, n.62, p.56-62, 2018.

ROGER, J. L. Refaire son métier: essai de clinique de l'activité. Paris: Érès, 2007.

ROUAT, S. Les processus individuels et organisationnels de construction de la santé au travail: prévention de la santé mentale au travail et analyse de dispositifs organisationnels. 2010. 503f. Thèse (Doctorat en Psychologie) - Université Lumière Lyon II, Lyon, 2010.

ROUAT, S.; SARNIN, P. Prévention des risques psychosociaux au travail et dynamique de maturation: le processus d'intervention comme opérateur de la transformation et du développement de la coopération. Activités, v.10, n.1, p.58-72, 2013.

ROUAT, S.; SARNIN, P. L'intervention en santé au travail: I'intérêt de l'étude de cas d'intervention. Le Travail Humain, v.4, n.81, p.331-363, 2019.

SCHELLER, L. Travail, affects, activité transférentielle. Activités, v.10, n.2, p.12-22, 2013. Disponível em: https://journals.openedition.org/activites/853. Acesso em: 01 jun. 2021.

TRENTIN, B. La cité du travail. Paris: Fayard, 2012.

UGHETTO, P. Organiser l'autonomie au travail. Limoges: Éditions Fyp, 2018.

VYGOTSKI, L. Conscience, inconscient, émotions. Trad. F. Sève e G. Fernandez. Paris: La Dispute, 2003.

ZITTOUN, M.; LARCHEVÊQUE, D. Une expérimentation sociale en clinique de l'activité. Rhizome, n.67, p.82-92, 2018. 
Recebido em setembro 2020.

Aprovado em setembro 2020. 